\title{
Optimal Plastic Analysis and Design of Pile Foundations Under Reliable Conditions
}

\author{
Majid Movahedi Rad ${ }^{1 *}$, Sarah Khaleel Ibrahim \\ ${ }^{1}$ Department of Structural and Geotechnical Engineering, Széchenyi István University, 9026 Győr, Egyetem tér 1, Hungary \\ * Corresponding author, e-mail: majidmr@sze.hu
}

Received: 23 October 2020, Accepted: 26 February 2021, Published online: 05 March 2021

\begin{abstract}
In this research, in order to evaluate the plastic limit load and also plastic design parameters of the long pile foundations subjected to horizontal loads, shakedown method is applied. In carrying out shakedown analysis and design methods, large plastic deformations and residual displacements could develop in the pile foundation which might lead to the failure of the structure. For this reason, complementary strain energy of residual forces proposed as a limit condition to control the plastic deformation of the pile structure. Furthermore, considering the uncertainties (strength, manufacturing, geometry) the limit conditions on the complementary strain energy of residual forces are assumed randomly and the reliability condition was formed by the use of the strict reliability index. The influence of the limit conditions on the plastic limit load and design parameters of the long pile in cohesionless soil subjected to lateral load were investigated and limit curves for shakedown load factors are presented. The numerical results show that the probabilistic given limit conditions on the complementary strain energy of residual forces have significant influence on the load bearing limit and the design parameters of pile foundations. The formulations of the reliability based problems lead to mathematical programming which were carried out by the use of non-linear algorithm.
\end{abstract}

Keywords

shakedown, pile foundation, reliability based design optimization, complementary strain energy

\section{Introduction}

In order to evaluate the uncertainties in engineering structures, two approaches have been improved in the recent years. The first method which is the deterministic design that considers the application of a global factor of safety or load factor. The second method which is the probabilistic design where the design information is characterized by having certain limits and recognized probability distributions. Despite the fact that the deterministic design has been preferable to use for many decades, the proper safety is not clear for a specific factor of safety. In the probabilistic design, randomly distributed variables used to define the uncertainties as the contribution of appearance for every feasible value of the variable is tested and the random variable values with the most frequent are related with the highest amounts in the probability density function. Generally, the uncertainties have a very extensive role and demand intensive computations in different fields of engineering. Kaveh and Seddighian [1] utilized robust meta-heuristic algorithms to optimize the slope stability problem. Csébfalvi [2-5] proposed new compliance minimization for robust topology optimization of structures with uncertain loading directions. Wang and Cao [6] evolved a reliability based design method for drilled shafts that integrates a Monte Carlo Simulation. Klammler et al. [7] investigated an approach for introducing a criteria of pile driving regarding individual pile foundations under axial loading. Li et al. [8] used the reliability based design method to calibrate the parameters of resistance considered in piles foundations design.

In the last decades, several studies were held about Pilesoil interaction. Qin and Guo [9] considered the nonlinear response of rigid piles subjected to lateral loading in sand by applying elastic-plastic solutions. They offered critical parameters for the limiting force profile that are useful in nonlinear design of piles loaded laterally. Keawsawasvong and Ukritchon [10] applied a numerical solution to find the capacity of the ultimate lateral load along the major or minor axes of rectangular pile in clay. Giannakos et al. [11] 
provided a nonlinear constitutive model for the cyclic behavior of piles in dry dense sand and a comparison was made between numerical and experimental results. Mucciacciaro and Sica [12] investigated the mechanical behavior of undrained clay by introducing a kinematic hardening model.

Considerable saving in material can be achieved by using the elastic-plastic analysis and design approaches. On the other hand, excessive residual displacements and large plastic deformations may develop, which can cause the failure of the structure. Over many years, literature reviews recommended several limit theorems for the residual displacements and plastic deformations (see e.g. Tin-Loi [13]; Liepa et al. [14]; Weichert and Maier [15] and Levy et al. [16]. In this research, a suitable computational method is presented when the complementary energy of the residual forces defined as a general measure of the plastic performance of the structures and the residual deformations need to be constrained by considering a limit for this amount of energy. This method was applied successfully for elastic-plastic analysis and for designing of several types of structures, Kaliszky and Lógó [17-21] introduced the application of the method for truss elements, while Movahedi Rad and Lógó [22] and Lógó et al. [23] applied the limit theorem in the case of framed steel structures, the method was applied for plastic limit analysis and design of pile foundation presented by Movahedi Rad [24]. In this paper, shakedown theorem for analyzing the plastic behavior of the laterally loaded piles is applied when the complementary energy of the residual forces defined as a general measure to control the plastic behavior of the pile foundation.

The remainder of this paper is prepared as follows: in Section 2 the elastic-plastic modelling of the long pile foundation is presented. The residual plastic limit equation is then introduced in Section 3 to control the plastic deformations. Moreover, reliability-based residual plastic limit is defined in Section 4 with applying complementary strain energy for residual forces. In addition, shakedown analysis and design methods are presented in Section 5. Then, an illustrated example is presented in Section 6 while the final section concludes the paper.

\section{Elastic-plastic modelling of the pile foundation}

Broms [25] assumed that different failure modes exist in short and long piles. A short pile with free head tilts or rotates about a point situated near its toe and passive resistance extends above and below the point of rotation. As in the case of long free head pile, pile cannot rotate or tilt because of its large passive resistance while the lower part stays almost vertical and the upper part deflects in flexure. Failure happens when the maximum bending moment exceeds the yield strength of the pile section and a plastic hinge forms at the point having the maximum bending moments as shown in Fig. 1.

Consider a free-head long pile with a constant cross section, at the depth $l$ which has no shear force, a plastic hinge with a plastic moment of $M^{p}$ will be formed. That $M^{p}$ can be calculated using elastic-plastic solutions suggested by Guo [26].

$$
\frac{M^{p}}{A_{L}}=\frac{1}{n+2}\left[\alpha_{0}^{n+1}+(n+1) \frac{H}{A_{L}}\right]^{\frac{n+2}{n+1}}-\left(\frac{\alpha_{0}^{n+2}}{n+2}+\frac{\alpha_{0} H}{A_{L}}\right)+\frac{M_{e}}{A_{L}}
$$

Where $A_{L}=\gamma^{\prime} N_{g} d^{1-n}$ related to the limiting force profile of cohesionless soil; $\gamma^{\prime}$ is the effective density of overburden soil; $N_{g}$ is the gradient to correlate the strength of undrained soil; $d$ is the outer diameter of the cylindrical pile; $n$ is the limitation power for force profile; $\alpha_{0}$ is the equivalent depth taking in consideration the resistance at the surface of the ground; $H$ is the lateral load and $M_{e}=H e$, $e$ is the distance from the mudline to lateral load.

The instructions to find the values of the parameters are suggested by Guo $[26,27]$ and the limiting force profile are assumed as advised for cohesionless soil by Broms [25].

\section{Theory of the residual plastic limit}

Let us assume that the concept of plastic analysis and design methods has been used to define the structure. In a result the internal plastic forces $Q^{p}$ will appear in the structure by applying the load $P_{0}$. Moreover, elastic deformations occur when the load is decreased under unloading and then the elastic internal forces-Qe will occur in the structure. Thus, the residual forces will remain in the structure after completing the unloading.

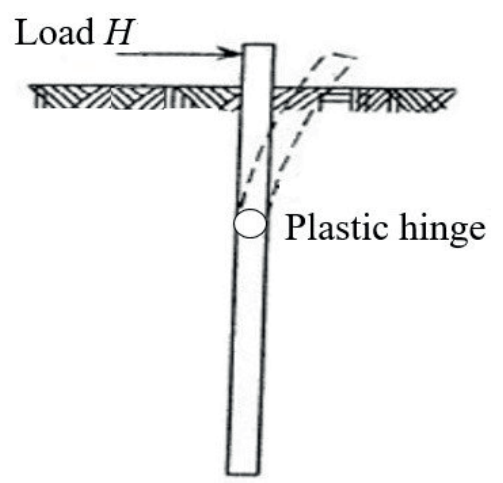

Fig. 1 Failure mode of the long free head pile subjected to horizontal load 
$Q^{r}=Q^{p}-Q^{e}$,

where

$Q^{e}=F^{-1} G^{T} K^{-1} P_{0}$.

Hereby, the flexibility matrix is denoted by $F$; $G$ is the geometrical matrix; also the stiffness matrix is denoted by $K$. Let us assume the positive-definite function, and the residual forces are used to determine the complementary energy.

$C_{p}=\frac{1}{2} \sum_{i=1}^{n} \frac{1}{S_{i}} \int_{0}^{l_{i}}\left(Q_{i}^{p}(s)-Q_{i}^{e}(s)\right)^{2} d s \geq 0$

As for here, $Q_{i}^{e}(s)$ and $Q_{i}^{p}(s)$ are the functions of elastic and plastic internal forces; $S_{i}$ expresses flexural stiffnesses and tensile stiffnesses for beam members and trusses, respectively.

A suitable computational method was suggested that the complementary energy of the residual forces can be explained as a general measure for the plastic performance of the structures and the residual deformations need to be constrained by considering limitations for this energy amount Kaliszky and Lógó [17] and Lógó et al. [23].

$\frac{1}{2} \sum_{i=1}^{n} \frac{1}{S_{i}} \int_{0}^{l_{i}}\left(Q_{i}^{p}(s)-Q_{i}^{e}(s)\right)^{2} d s-C_{p 0} \leq 0$,

where $C_{p 0}$ is a suitable permissible energy value for $C_{p}$. And now let us consider the case of beam elements:

$C_{p}=\frac{1}{2 E} \sum_{i=1}^{n} \frac{1}{I_{i}} \int_{0}^{l_{i}}\left(M_{i}^{r}(s)\right)^{2} d s$

the complementary energy is computed by the residual internal forces.

In here $l_{i},(i=1,2, \ldots, n)$ indicates the members length of the beam, the moment of inertia of the beam elements is represented by, $l_{i}$ while $M_{i}^{r}(s)$ denotes to the residual moment of the beam members and $E$ is the Young's modulus. On the other hand, the moments $M_{i 1}^{r}$ and $M_{i 2}^{r}$ are applying at the ends of the members of the beam. The integral function in Eq. (4) can be expressed as:

$\int_{0}^{l_{i}}\left(M_{i}^{r}(s)\right)^{2}=\frac{1}{3}\left[\left(M_{1}^{r}\right)^{2}+\left(M_{1}^{r}\right)\left(M_{2}^{r}\right)+\left(M_{2}^{r}\right)^{2}\right.$.

By applying the Eq. (6), the plastic deformations constrained as an appropriate limit value $C_{p 0}$ is introduced.

$\frac{1}{6 E} \sum_{i=1}^{n} \frac{l_{i}}{I_{i}}\left[\left(M_{1}^{r}\right)^{2}+\left(M_{1}^{r}\right)\left(M_{2}^{r}\right)+\left(M_{2}^{r}\right)^{2}\right]-C_{p 0} \leq 0$
Also, a limit function G(.) can be produced by the use of Eq. (8):

$$
G\left(C_{p 0,} M^{r}\right)=C_{p 0}-\frac{1}{6 E} \sum_{i=1}^{n} \frac{l_{i}}{I_{i}}\left[\left(M_{1}^{r}\right)^{2}+\left(M_{1}^{r}\right)\left(M_{2}^{r}\right)+\left(M_{2}^{r}\right)^{2}\right] .
$$

\section{Theory of reliability-based residual plastic limit}

By assuming that $X_{R}$ presents the non-negative bound for the statically admissible forces $X_{S}$ with probability density functions $f_{R}\left(X_{R}\right)$ and $f_{S}\left(X_{S}\right)$, respectively. Failure probability can be determined from the following equations:

$$
P_{f}=P\left[X_{R} \leq X_{S}\right]=\iint_{X_{R} \leq X_{S}} f_{R}\left(X_{R}\right) f_{S}\left(X_{S}\right) d X_{R} d X_{S} .
$$

The above equation has to be evaluated numerically for most of the distributions of $X_{R}$ and $X_{S}$. Another alternative formulation of the above case is considered in the terms of the so-called limit state function which expressed by:

$G\left(X_{R}, X_{S}\right)=X_{R}-X_{S} \leq 0$.

Observing that $G \leq 0$ defines the failure event, consequently the probability of failure is presented by:

$P_{f}=F_{G}(0)$.

Where the function of the cumulative distribution of the limit state surface is represented by $F_{G}(0)$. Let us assume that the constrains for the complementary energy of the residual forces is specified by uncertainties and it follows the normal density function with given $\bar{C}_{p 0}$ that represent the mean value and the variance which denoted by $S_{w}$. The probability of the failure function can be found by the following equation:

$P_{f, \text { calc }}=\int f\left(\bar{C}_{p 0}, S_{w}\right) d x$.

A reliability boundary condition can be created by using the strict safety index as the following:

$\beta_{\text {target }}-\beta_{\text {calc }} \leq 0$.

where $\beta_{\text {target }}$ and $\beta_{\text {calc }}$ are determined as follows:

$\beta_{\text {target }}=-\Phi^{-1}\left(P_{f, \text { target }}\right)$,

$\beta_{\text {calc }}=-\Phi^{-1}\left(P_{f, \text { calc }}\right)$.

In both Eqs. (15) and (16), $\Phi$ represents the cumulative distribution function of the normal distribution function.

\section{Shakedown analysis and design methods}

Taking into consideration the parameters of the load $m_{1} \geq 0, m_{2} \geq 0$, shown in Fig. 2 that the long pile in cohesionless and it is under two separate constant loads $P_{1}$ and $P_{2}$. 
A shakedown load parameter $m_{s h}$ can be calculated for every loading combination, $W_{i}=\left[m_{1} P_{1}, m_{2} P_{2}\right]$. As a result, a limit state curves can be created in $m_{1}$ and $m_{2}$ plane by using these parameters as clarified in Fig. 3.

Taking in account the permissible bending moment fields $M_{j}$, achieving a statically admissible stable shakedown load parameter $m_{s h}$ from the condition that even the maximum bending moment does not exceed the fully plastic moment, i.e. $\max \left|M_{j}\right| \leq M^{P}$.

Moreover, $M^{r}$ satisfies the equilibrium equation as the solution approach is based on the static theorem of shakedown analysis.

$G M^{r}=0$

During the loading, the structure will not undertake unlimited plastic displacements as it confirmed in Eq. (17), however, it doesn't give us any information about permanent displacements remained in the structure after the shake down.

In order to restrict the permanent displacements complementary energy of the residual forces which is explained as a general measure of the plastic performance of the structures and the residual deformations are constrained by Eq. (8).

The equation of the elastic internal moment force can be derived from Eq. (18) as follows:

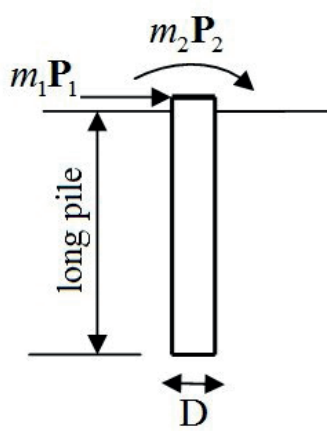

Fig. 2 Load combination on the pile

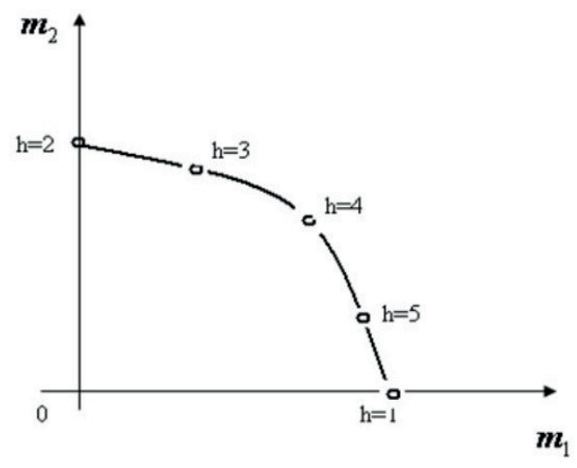

Fig. 3 limit state curve and safe domain
$M^{e}=F^{-1} G K^{-1} m_{s h} W_{i}$.

Also, Eq. (19) defines the yields condition while the $M^{P}$ can be calculated using Eq. (1) that proposed by Guo [26].

$-M^{p} \leq M^{r}+\max M^{e} \leq M^{p}$

The material redistribution is controlled by the following equation:

$\sum_{i=1}^{n} A_{i} l_{i}-V_{0} \leq 0$

Where $A_{i}$ and $l_{i}$ represents the cross-sectional area and length of each element, respectively.

\subsection{Deterministic shakedown problem}

As for the deterministic method, residual plastic deformations of the pile structures are bounded with applying allowable energy value $C_{p 0}$ :

$$
\left.\begin{array}{l}
m_{s h}=\max \\
G M^{r}=0 \\
-M^{p} \leq M^{r}+\max M^{e} \leq M^{p} \\
M^{e}=F^{-1} G K^{-1} m_{s h} W_{i} \\
\frac{1}{6 E} \sum_{i=1}^{n} \frac{l_{i}}{I_{i}}\left[\left(M_{1}^{r}\right)^{2}+\left(M_{1}^{r}\right)\left(M_{2}^{r}\right)+\left(M_{2}^{r}\right)^{2}\right]-C_{p 0} \leq 0 \\
\sum_{i=1}^{n} A_{i} l_{i}-V_{0} \leq 0
\end{array}\right\}
$$

\subsection{Probabilistic shakedown formulation}

Nonlinear algorithm is used to execute this mathematical optimization problem and by considering the probabilistic method, the bound can be defined with the determining of the safety index $\beta$ :

$$
\left.\begin{array}{l}
m_{s h}=\max \\
G M^{r}=0 \\
-M^{p} \leq M^{r}+\max M^{e} \leq M^{p} \\
M^{e}=F^{-1} G K^{-1} m_{s h} W_{i} \\
\beta_{\text {target }}-\beta_{\text {calc }} \leq 0 \\
\sum_{i=1}^{n} A_{i} l_{i}-V_{0} \leq 0
\end{array}\right\}
$$

\subsection{Alternative design formulation}

By altering the objective function and the last constraint, an alternative design formulation can be introduced as follows: 


$$
\left.\begin{array}{l}
\text { Minimize } V=\sum_{i} A_{i} l_{i} \\
G M^{r}=0 \\
-M^{p} \leq M^{r}+\max M^{e} \leq M^{p} \\
M^{e}=F^{-1} G K^{-1} m_{s h} W_{i} \\
\beta_{\text {target }}-\beta_{\text {calc }} \leq 0 \\
m_{\text {sh }}-m_{0} \leq 0
\end{array}\right\}
$$

Generally, the formulations of the reliability based problems lead into mathematical programming which were carried out by the use of non-linear algorithm. Moreover, the nonlinear mathematical programming formulation Eq. (23) leads to the same optimal solution presented in problem Eq. (22) which can be proved by the use of the optimality conditions.

\section{Numerical examples}

In order to evaluate the shakedown theories and the methods of solutions explained previously, a mathematical nonlinear programming procedure is developed where the safe limit loading condition of a lateral loaded long pile for deterministic and probabilistic bounds on the magnitude of the complementary energy of the residual forces has to be calculated.

A numerical example is used to evaluate the application of these theories. This example demonstrates a long pile with free head and it is subjected to lateral load and bending moment that act at its top where the diameter of the pile is $D=0.4 \mathrm{~m}$ (Fig. 4). The constant loads are $P_{1}=H=0 \mathrm{KN}$, $P_{2}=M=24 \mathrm{KN}$, the flexural stiffness $E I=117.47 \mathrm{MN} \mathrm{m}^{2}$. The vertical pile embedded in cohesionless soil, the density of soil is $1900 \mathrm{~kg} / \mathrm{m}^{3}$; Young's Modulus $=170 \mathrm{MPa}$ poisson's ratio $=0.3$ and friction angel $=41^{\circ}$.

The analyzing of the five loading cases $(h=1,2 \ldots, 5)$ shown in Table 1 are taken into consideration. For each loading case a shakedown load multiplier $m_{s}$ can be calculated. Making use of these multipliers, a limit curve can be constructed in the plane $m_{1}$ and $m_{2}$.

Figs. 5 and 6 are showing the results and it can be seen that the limit load state domains are in two different functions for deterministic and probabilistic problems. In Fig. 5 as for deterministic problem, the state of limited load domains are considered in the case of different permissible energy value for $C_{p 0}$ While in the case of probabilistic problem the state of limited load domains are clarified for different mean values of the complementary energy of the residual forces $\bar{C}_{p 0}(40 ; 45 ; 50 ; 55)$ with variance $s_{w}=3$, target reliability index $\beta_{\text {target }}=3.2$ and given probability of

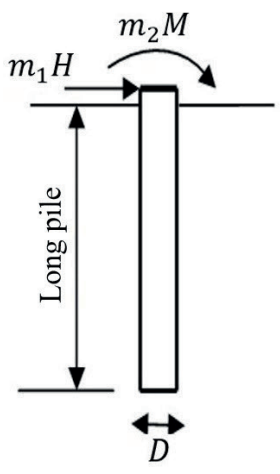

Fig. 4 Loads applied on the free head pile

Table 1 Load combinations

\begin{tabular}{cccc}
\hline$h$ & Multipliers & Loads & $\begin{array}{c}\text { Load } \\
\text { multipliers }\end{array}$ \\
\hline 1 & $m_{2}=0$ & $\boldsymbol{Q}_{1}=\boldsymbol{P}_{1}$ & $m s_{1}$ \\
2 & $m_{1}=0$ & $\boldsymbol{Q}_{2}=\boldsymbol{P}_{2}$ & $m s_{2}$ \\
3 & $m_{1}=0.5 m_{2}$ & $\boldsymbol{Q}_{3}=\left[0.5 \boldsymbol{P}_{1},\left(0.5 \boldsymbol{P}_{1}+\boldsymbol{P}_{2}\right), \boldsymbol{P}_{2}\right]$ & $m s_{3}$ \\
4 & $m_{1}=m_{2}$ & $\boldsymbol{Q}_{4}=\left[\boldsymbol{P}_{1},\left(\boldsymbol{P}_{1}+\boldsymbol{P}_{2}\right), \boldsymbol{P}_{2}\right]$ & $m s_{4}$ \\
5 & $m_{1}=2 m_{2}$ & $\boldsymbol{Q}_{5}=\left[2.0 \boldsymbol{P}_{1},\left(2.0 \boldsymbol{P}_{1}+\boldsymbol{P}_{2}\right), \boldsymbol{P}_{2}\right]$ & $m s_{5}$ \\
\hline
\end{tabular}

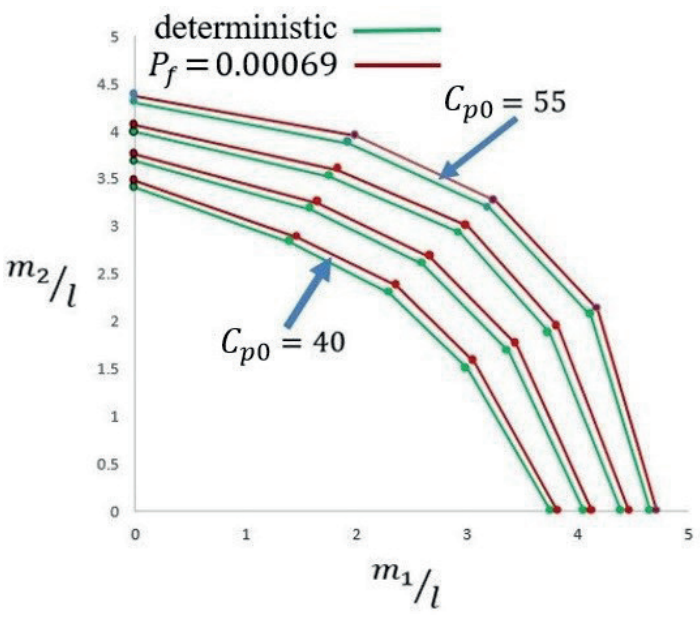

Fig. 5 State of limited load domain for long pile

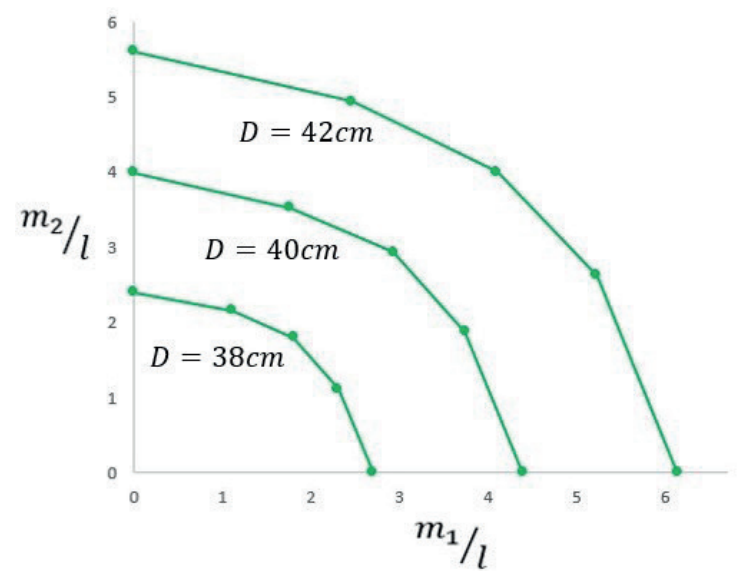

Fig. 6 Safe loading domain of shakedown load multipliers 
failure $P_{f}=0.00069$. The Pile subjected to lateral loads does not fail, if the load parameters $m_{1}$ and $m_{2}$ locates inside or on the limit state curve.

Fig. 6 illustrates the deterministic solution technique results for piles with different diameters. In that figure we can notice the safe loading domain of shakedown load multipliers for given permissible energy value $C_{p 0}=50$.

\section{Conclusions}

The shakedown limit analysis is described in this paper in order to determine the lateral load capacity for long pile. Moreover, given bound on the complementary strain energy of the residual forces is applied in order to control the plastic behavior of the structure for deterministic and

\section{References}

[1] Kaveh, A., Seddighian, M. R. "Optimization of Slope Critical Surfaces Considering Seepage and Seismic Effects Using Finite Element Method and Five Meta-Heuristic Algorithms", Periodica Polytechnica Civil Engineering, 2020.

https://doi.org/10.3311/PPci.17098

[2] Csébfalvi, A. "A New Compliance-function-shapeoriented Robust Approach for Volume-constrained Continuous Topology Optimization with Uncertain Loading Directions", Periodica Polytechnica Civil Engineering, 62(1), pp. 219-225, 2018.

https://doi.org/10.3311/PPci.11398

[3] Csébfalvi, A., Lógó, J. "Investigation of the possible numerical treatments of a compliance-function-shape-oriented robust truss sizing model with uncertain loading directions", Advances in Engineering Software, 149, Article No. 102899, 2020.

https://doi.org/10.1016/j.advengsoft.2020.102899

[4] Csébfalvi, A. "Critical Investigation of the Combined Compliance Average and Spreading Measures in the Robust Topology Optimization with Uncertain Loading Magnitude and Direction", Periodica Polytechnica Civil Engineering, 64(4), pp. 1275-1283, 2020. https://doi.org/10.3311/PPci.16681

[5] Csébfalvi, A. "Robust Topology Optimization: A New Algorithm for Volume-constrained Expected Compliance Minimization with Probabilistic Loading Directions using Exact Analytical Objective and Gradient", Periodica Polytechnica Civil Engineering, 61(1), pp. 154-163, 2017.

https://doi.org/10.3311/PPci.10214

[6] Wang, Y., Cao, Z. "Expanded reliability-based design of piles in spatially variable soil using efficient Monte Carlo simulations", Soils and Foundations, 53(6), pp. 820-834, 2013.

https://doi.org/10.1016/j.sandf.2013.10.002

[7] Klammler, H., McVay, M., Herrera, R., Lai, P. "Reliability based design of driven pile groups using combination of pile driving equations and high strain dynamic pile monitoring", Structural Safety, 45, pp. 10-17, 2013.

https://doi.org/10.1016/j.strusafe.2013.07.009 probabilistic problems. Also, limit curves are provided for the multipliers of the shakedown limit load. The numerical analysis demonstrates that the given mean values and different expected probability on the bound of the complementary strain energy of the residual forces can affect significantly on the magnitude of the plastic limit load.

\section{Acknowledgment}

The paper was written with the support of the project titled "Internationalisation, initiatives to establish a new source of researchers and graduates and development of knowledge and technological transfer as instruments of intelligent specialisations at Széchenyi István University" (project number: EFOP-3.6.1- 16-2016-00017).

[8] Li, J. P., Zhang, J., Liu, S. N., Juang, C. H. "Reliability-based code revision for design of pile foundations: Practice in Shanghai, China", Soils and Foundations, 55(3), pp. 637-649, 2015.

https://doi.org/10.1016/j.sandf.2015.04.014

[9] Qin, H., Guo, W. D. "Nonlinear response of laterally loaded rigid piles in sand", Geomechanics and Engineering, 7(6), pp. 679-703, 2014.

https://doi.org/10.12989/gae.2014.7.6.679

[10] Keawsawasvong, S., Ukritchon, B. "Ultimate lateral capacity of two dimensional plane strain rectangular pile in clay", Geomechanics and Engineering, 11(2), pp. 235-252, 2016.

https://doi.org/10.12989/gae.2016.11.2.235

[11] Giannakos, S., Gerolymos, N., Gazetas, G. "Cyclic lateral response of piles in dry sand: Finite element modeling and validation", Computers and Geotechnics, 44, pp. 116-131, 2012. https://doi.org/10.1016/j.compgeo.2012.03.013

[12] Mucciacciaro, M., Sica, S. "Nonlinear soil and pile behaviour on kinematic bending response of flexible piles", Soil Dynamics and Earthquake Engineering, 107, pp. 195-213, 2018.

https://doi.org/10.1016/j.soildyn.2017.12.025

[13] Tin-Loi, F. "Optimum shakedown design under residual displacement constraints", Structural and Multidisciplinary Optimization, 19, pp. 130-139, 2000.

https://doi.org/10.1007/s001580050093

[14] Liepa, L., Blaževičius, G., Merkevičiūtè, D., Atkočiūnas, J. "Structural shakedown: a new methodology for estimating the residual displacements", Journal of Civil Engineering and Management, 22(8), pp. 1055-1065, 2016. https://doi.org/10.3846/13923730.2016.1217924

[15] Weichert, D., Maier, G. (eds.) "Inelastic behaviour of structures under variable repeated loads", Springer, Vienna, Austria, 2002. https://doi.org/10.1007/978-3-7091-2558-8

[16] Levy, N. H., Einav, I., Hull, T. "Cyclic shakedown of piles subjected to two-dimensional lateral loading", International Journal for Numerical and Analytical Methods in Geomechanic, 33(10), pp. 1339-1361, 2009. https://doi.org/10.1002/nag.775 
[17] Kaliszky, S., Lógó, J. "Elasto-Plastic Analysis and Optimal Design with Limited Plastic Deformations and Displacements", In: Structural and Multidisciplinary Optimization, Proceedings of the First World Congress of Structural and Multidisciplinary Optimization, Goslar, Germany, May, 28-June, 2, 1995, pp. 465-470.

[18] Kaliszky, S., Lógó, J. "Discrete Optimal Design of Elasto-Plastic Trusses Using Compliance and Stability Constraints", Structural Optimization, 15, pp. 261-268, 1998. https://doi.org/10.1007/BF01203541

[19] Kaliszky, S., Lógó, J. "Optimal Strengthening of Elasto-Plastic Trusses with Plastic Deformation and Stability Constraints", Structural Optimization, 18, pp. 296-299, 1999. https://doi.org/10.1007/BF01223313

[20] Kaliszky, S., Lógó, J. "Optimal plastic limit and shakedown design of bar structures with constraints on plastic deformation", Engineering Structures, 19(1), pp. 19-27, 1997. https://doi.org/10.1016/S0141-0296(96)00066-1

[21] Kaliszky, S., Lógó, J. "Plastic behaviour and stability constraints in the shakedown analysis and optimal design of trusses", Journal of Structural and Multidisciplinary Optimization, 24, pp. 118-124,2002. https://doi.org/10.1007/s00158-002-0222-2
[22] Movahedi Rad, M., Lógó, J. "Plastic behavior and stability constraints in the reliability based shakedown analysis and optimal design of skeletal structures", Asian Journal of Civil Engineering, 12(4), pp. 395-413, 2011.

[23] Lógó, J., Movahedi Rad, M., Knabel, J., Tauzowski, P. "Reliability based design of frames with limited residual strain energy capacity", Periodica Polytechnica Civil Engineering, 55(1), pp. 13-20, 2011. https://doi.org/10.3311/pp.ci.2011-1.02

[24] Movahedi Rad, M. "Reliability Based Analysis and Optimum Design of Laterally Loaded Piles", Periodica Polytechnica Civil Engineering, 61(3), pp. 491-497, 2017. https://doi.org/10.3311/PPci.8756

[25] Broms, B. B. "Lateral Resistance of Piles in Cohesionless Soils", Journal of the Soil Mechanics and Foundations Division, 90(3), pp. 123-156, 1964.

[26] Guo, W. D. "On limiting force profile, slip depth and response of lateral piles", Computers and Geotechnics, 33(1), pp. 47-67, 2006. https://doi.org/10.1016/j.compgeo.2006.02.001

[27] Guo, W. D. "Theory and Practice of Pile Foundations", CRC Press, London, UK, 2012. 